\title{
Artificial Intelligence Design Suggestions for Apparel Retail Counters
}

\author{
Dr. Nidhi Sharma ${ }^{1} \mid$ Dr. Alok Sharma ${ }^{2}$

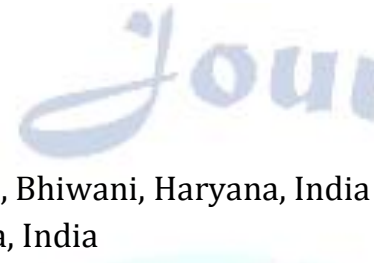 \\ ${ }^{1}$ Department of Computer Engineering, TIT\&S, Bhiwani,
${ }^{2}$ Om Sterling Global University, Hisar, Haryana, India
}

To Cite this Article

Dr. Nidhi Sharma and Dr. Alok Sharma, "Artificial Intelligence Design Suggestions for Apparel Retail Counters", International Journal for Modern Trends in Science and Technology, 6(9S): 242-244, 2020.

\section{Article Info}

Received on 25-August-2020, Revised on 08-September-2020, Accepted on 12-September-2020, Published on 18-September-2020.

\section{ABSTRACT}

Artificial Intelligence is the requirement felt widely in retail industry support system, especially in Apparel Retail counters. On different occasions, functions, parties and celebrations, the shopping is done using these Apparel retail counters. Artificial Intelligence is an area of computer science which simulates the human intelligence and human sensory abilities. So, Artificial Intelligence is becoming an imperative tool for the retail counters to enhance the quality, improve customer's experience, automation, and to lower the operating costs. This paper will discuss how Artificial Intelligence is influencing the retail counters by automation of cash management, improving customer's experience and providing other supports for adjustment of prices and prediction of prices considering seasonal as well as occasional effects.

KEYWORDS:, Artificial Intelligence, Supervised learning, Unsupervised learning, Retail Counters, AI Chatboot.

\section{INTRODUCTION}

With the emergence of 24/7 Internet, the customers can save their time and can shop online at their own convenience. AI machines which facilitate retail counters are working with the following major components (support system) in them. First, sensing devices and second, calculation support system along with output devices like vocal communication, printouts and displays in different forms. As per sensing devices are concerned, most of them are camera, barcode readers, sound recorder, electronic sensors etc. Thus for logical programming feature, calibration, decision support system mainly supervised and unsupervised learning concepts are used.

\section{Supervised learning:}

In case of supervised learning previous (old) data is available in database to guide the decision taken by AI machine. In case of supervised learning complete guidance and help is available to calibrate the system such that all future decisions are correct.

\section{Unsupervised learning:}

In case of Unsupervised learning previous (old) data is not available in database to guide the decision taken by AI machine. In case of unsupervised learning no guidance and help is available to calibrate the system and chances of right decision are probable only not guaranteed. 

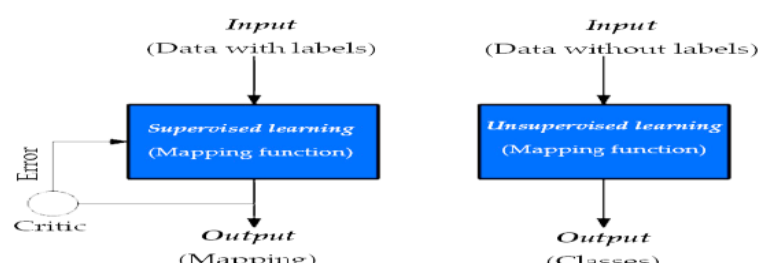

Fig1: Types of Learning Techniques in Retail Counters

\section{AI DESIGN SUGGESTIONS FOR RETAIL COUNTERS}

Artificial Intelligence is influencing the retail counters by automation of cash management, improving customer's experience and providing other supports for adjustment of prices and prediction of prices considering seasonal as well as occasional effects. Some of the applications of Artificial Intelligence in retail counter are:

1) Cash management without human help,

2) Customer guide to assist in shopping and to provide assistance in store,

3) Adjustment of Prices and Prediction of Prices.

\section{1) CASH MANAGEMENT WITHOUT HUMAN HELP}

Now a days, the warehouses in developed countries are taking help of robots for cash management. For this work, Robots considers two main conditions:

1) If customer pick any item

2) If customer put back any item

The item picked by customer is consider as purchased item and item kept back is considered as unpurchased. So this way, Number of item purchased cost towards customer bill and on exit from warehouse customer has to pay only for purchased items. By doing so, with the help of simple robots with sensors and billing facility like a robotised POS (Point of sale) facility this feature of cash management is handled. For this facility the concept of limited supervised learning technique is used as an example of all situations of POS(Point of sale) are available from many years in the database of warehouses to make the robotised management of cash counters. This process of cash management without human needs more electronic sensors and printing devices rather than complicated Artificial Intelligence programming. That's why, the limited supervised learning is mention in the above lines.
This feature is to help the customer in shopping and to improve customer shopping experience. Customers used to chat with a counter clerk known as Chatboot who knew the products and assembled orders. It matches with artificial passenger application of AI in Vehicle in which to accompany the driver, to monitor drivers activity and to improve his comfort, to entertain him, to make him aware of risky situation(warnings), to refresh his mood if driver feels bore many sensors are fitted inside the vehicle. Similarly, in retail counter AI Chatboot should help customer in improving his shopping skills by making customer aware of various schemes available, discounts, observing his shopping interest, making customer aware of all possible options of purchase of item of customer's interest responding customer's query, providing best answers to Customer's Query, helping customer in locating items, upcoming schemes and sales, other facilities available like sanitization, rules and regulations in CORONA like situations do's and Donot's. For providing this type of facility in warehouses using AI the requirement of system are:

a) Updating of various schemes, tokens, discounts and other data required to handle query of customer in AI Chatboot machine database

b) A database with all possible values of features of all available items for best purchase options of every item in the warehouse.

c) A track record of likes and dislikes pattern of previous customer behaviour

d) Sensors to judge the behaviour of customer and react accordingly with AI logical support to answer in best way.

For providing this type of facility to warehouses requires supervised learning of AI system from the data available in database of warehouse about shopping patterns and queries came across in the past.

Next requirement is the calibration of system to judge the personality of customer with the help of various type of sensors and logical support available in the AI Chatboot.

Normally, supervised learning with available database mentioned above is sufficient to handle the query of customers but for more advance systems personality judgement may be included to enhance the Quality of work which requires calibration of system in starting to judge human behaviours for better results.

\section{2) CUSTOMER GUIDE TO ASSIST IN SHOPPING AND TO PROVIDE ASSISTANCE IN STORE}




\section{3) ADJUSTMENT OF PRICES AND PREDICTION OF PRICES}

The price adjustment systems are use to fix prices of items by monitoring the outcomes of different price strategies. To adjust the prices, calculations are made by analysing costs, quality and other parameters of available products in market, various promotions activities, sale data and its trends along with other available data. During price adjustment all type of customers are considered, target of sale are to be met by presenting the best offers and getting new customers to boost sales.

For price forecasting (prediction) the market demand of the product, seasonal effects, characteristics and date of release of new products etc are considered.

This feature for support of retail counter requires maximum efforts in comparison of other supports where data is quantitatively verifiable from the available database to give best results. This feature to handle adjustment of prices and prediction of prices requires critical reasoning support, inclusion of all affecting parameters, and calibration of system to give good results.

\section{CONCLUSION}

In this paper the use of AI with design suggestions in Apparel retail counters is discussed .It has been observed from above discussion that AI machines take decisions mostly in two ways:

1) The decision is quantitatively verifiable from the available database of Retail counters. In such cases, the possibility of taking wrong decisions by AI machines is nill. So, such types of machines for handling such scenarios are suggested for medium and large retail counters. As are the first two cases of application in the paper i.e cash management without human and Chatboot to improve customer experience. Similar types of automation machines with nearly similar features are visible now a days for tickets generation on metro platforms.

2) In some cases AI machines are used for critical analysis and predictions where decision of $\mathrm{AI}$ machine is not verifiable from available database. So there are chances of mistake in decision making as machine has to be calibrated based on many factors which requires the supervision of core technical team to take right decisions and inclusion of upcoming factors which come with time in picture. Such AI machines are suggested to be used in large scale industry counters where a team of intellectuals to monitor is affordable.

\section{REFERENCES}

[1] http://www.aindralabs.com

[2] http://www.insider-trends.com

[3] http://www.v-count.com

[4] http://www.altexsoft.com

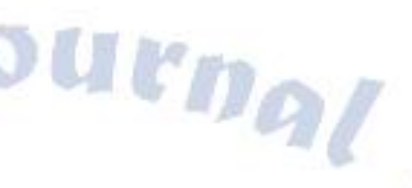

